\section{Living language}

\section{Words and phrases can take on a life of their} own as dialects.

$\mathrm{I}$ f you're shilpit, you'll be able to shuck on your dead ronking kecks as far as your oxters. It could be war nor worse to be idle as Ludlum's dog, but playing acky 1-2-3 would have you jiffling in your gansey.

No, this isn't an excerpt from an unseen fragment of A Clockwork Orange, in which Alex and his Droogs commit some act of unmentionable mayhem. Neither is it a lyric exhumed from that memorable yet entirely fictional folk singer Rambling Syd Rumpo (played by the late Kenneth Williams in the 1960s BBC radio series Round the Horne).

Those first two sentences contain words still used somewhere in England today, and show that dialect is very much alive and yet to be killed off by globalization. The British Library in London is gamely trying to keep track of all this in its Evolving English WordBank, a project to record English dialects and slang from around the world (see go.nature.com/2n4aamf).

That the word 'English' is preceded in the name of the library project by the word 'evolving' is no empty alliterative affectation. Dialects are regional variants of language, and language is a protean thing whose evolution follows the same principles as those for genes and species in nature. Dialects, if left alone for long enough, can evolve into languages that continue to change. Middle Scots, for example, which evolved into the Scots immortalized by the poet Robert Burns, is thought by some to stem from Northumbrian, a variety of Old English, but is less influenced by French than its southern cousins are. And it probably has more borrowings from Norse.

Before the invention of printing, English was less a language than a collection of regional dialects loosely flung together like kittens in a sack. A reader of modern English can just about get the gist of Geoffrey Chaucer's fourteenth-century The Canterbury Tales without a dictionary. The same reader, however, would find Sir Gawain and the Green Knight, written at around the same time somewhere in the northwest of England, almost unintelligible.

For in the same way that dialects are languages in the making, so, too, do languages and dialects die out. We understand Chaucer because our own strain of English evolved from it. The English of Gawain, however, became extinct. Except, perhaps, for a bare few dwingey chimbles sniggled from the march of progress.
ANNOUNCEMENT

\section{Transparency upgrade for Nature journals}

Tn 2013, this journal and many of the Nature research journals 1 announced initiatives aimed at "reducing our irreproducibility" (Nature 496, 398; 2013). These included a life-sciences checklist for authors and editors intended to improve the transparency of the statistical and methodological aspects of laboratory work, together with abolition of length limits in online methods descriptions and greater attention to statistical evaluation.

At the same time, we encouraged the publishing of step-bystep protocols that are linked to the published papers and made available through the open repository Protocol Exchange. And, complementing our policy of mandated deposition for certain data types, we strongly encouraged or (in some cases) mandated the provision of source data underlying graphical items.

Anecdotal feedback suggests that our application of the checklists - which represent extra time and effort by both authors and editors - has been much appreciated, although not by everybody: author compliance can be an issue, and we will soon announce steps to improve matters.

We have continued to implement policies that support reproducible research - by strengthening requirements for code availability in 2014, and introducing reporting standards for cell-line source and authentication details in 2015. A data policy, effective in 2016, introduces a mandatory dataavailability statement in all papers published in the Nature journals and encourages data citation. Another notable step forward comes with the introduction of 'registered reports' at Nature Human Behaviour, a format intended to minimize research bias by basing acceptance on the significance of the question and the robustness of the methods, rather than the outcome of the results.

On other fronts, we have explored reproducibility-related issues in our news and opinion pages (see go.nature.com/2ca0ej1). We have also developed the checklist approach by implementing new modules for specialized areas of research afflicted by poor reporting of experimental details - in photovoltaics, laser physics and functional magnetic resonance imaging.

This week sees a further development. Nature and the Nature journals are published by Springer Nature, whose publications also include Scientific Reports, Scientific Data, Nature Partner Journals and BioMed Central and Springer journals. All of these publications are now committed to becoming formal signatories to the Transparency Openness Promotion (TOP) guidelines. The TOP guidelines (https://cos.io/top) focus on transparency and openness in research design, data and materials to enable reproducible research. They were developed with the involvement of journals (including the Nature group), and were introduced in 2015.

The guidelines consist of eight standards - citation standards, data transparency, analytic methods (code) transparency, research materials transparency, design and analysis transparency, preregistration of studies, preregistration of analysis plans, and replication - with three levels of increasing rigour. The TOP guidelines provide a common set of standards and a useful framework for advancing an agenda for reproducible research, but uptake of individual standards by Springer Nature journals will be guided by disciplinary norms.

All of these initiatives should help those wishing to replicate our papers. The Nature journals do not have a dedicated format for replication studies, but we do consider high-value replications, subjecting them to the same criteria as other submitted studies. Scientific Data welcomes submissions describing data sets from replication studies, and recently launched an online collection highlighting a series of replication data sets it had published over the past six months. The collection was organized in partnership with the Open Science Framework, a service from the non-profit Center for Open Science in Charlottesville, Virginia, which has coordinated the development of the TOP guidelines.

As illustrated at meeting on reproducibility issues and remedies last week at the US National Academy of Sciences, this journey is far from complete, and all of us in the research landscape are stakeholders in its progress. Nature will continue to play its part in championing the increased robustness of research. 